\title{
IMPACT OF CPP-ACPF AND SODIUM FLUORIDE REMINERALIZING PASTS ON SURFACE TEXTURE OF RESIN COMPOSITES
}

\author{
Nabawy A. Alrobeigy* and Yasser A. Abed**
}

\begin{abstract}
Purpose: To investigate and compare the impact of casin phosphopeptide-amorphous calcium phosphate with fluoride (CPP-ACPF) and sodium fluoride, remineralizing pasts, on surface texture of four different resin composites.
\end{abstract}

Methods: 20 disc specimens $(5 \mathrm{~mm} \times 2 \mathrm{~mm})$ were prepared from each of four resin composites that belong to the categories of conventional (Filtek Z250 XT; F250), flowable (Filtek Z350 XT; F350), high viscosity bulk-fill (Filtek Bulk Fill Restorative Posterior; FBF), and self-adhering flowable (Vertise Flow; VF). After polishing, the specimens of each material were divided into four groups $(\mathrm{n}=5)$ : group 1: without treatment, dry-stored; group 2: without treatment, water-stored; group 3: treated with GC Tooth Mousse Plus (TMP) $15 \mathrm{~min} /$ once daily and stored in distilled water; and group 4: treated with Clinpro White Varnish (CWV) $15 \mathrm{~min} /$ once daily and stored in distilled water. All specimens were stored for 15 days at $37^{\circ} \mathrm{C}$. The surface roughness was determined using non-contact 3D Optical Profiler. Three exposures were performed on top surface of each specimen. Statistical analysis was performed using ANOVA followed by Tukey HDS.

Results: For all materials investigated; the roughness values of TMP-treated group were not affected $(P>0.05)$ compared to control group, while they were significantly $(P<0.001)$ reduced compared to water-stored, except for VF. However, the roughness values of CWV-treated group were significantly $(\mathrm{P}<0.001)$ increased compared to both control and water-stored groups, for all materials. The values of all roughness parameters of TMP-treated group of each composite tested were significantly $(\mathrm{P}<0.001)$ lower than those of $\mathrm{CWV}$-treated group, except for $\mathrm{Sp}$ and $\mathrm{Sv}$ parameters regarding VF.

Conclusions: TMP produced a significant surface smoothening of nano-composites used in this study, while CWV caused a significant increase in roughness values of all materials. Topical application of TMP could be used clinically without adverse effects on surface texture of resin composites.

KEYWORDS: CCP-ACP, sodium fluoride, surface roughness, resin composites.

\footnotetext{
Assistant Professor, Department of Dental Biomaterials, Faculty of Dentistry, Tanta University, Egypt.

** Assistant Professor, Department of Operative Dentistry, Faculty of Dentistry, October 6 University, Egypt.
} 


\section{INTRODUCTION}

The use of resin composites restorative materials has substantially increased over recent years due to increased esthetic demand of patients; improved physical and mechanical properties of composites; and advances in adhesive technology and bonding procedures ${ }^{[1-3]}$. Various types of composite materials with different physical properties and chemical structures were developed over the last two decades ${ }^{[4]}$. Improvement in restorative composites were accomplished by optimizing the fillers (loading, size, shape, and distribution) as well as resin matrix monomers ${ }^{[5,6]}$. One of the most significant advances in the last few years is the application of nanofiller technology to composite materials ${ }^{[4,5]}$. The introduction of nano-composites with reduced polymerization shrinkage; improved physical, mechanical, and optical properties; increased wear resistance, and high gloss retention have been lead to the possibility of using these composites for anterior and posterior restorations ${ }^{[1,6-9]}$.

Recently, a new generation of so-called "bulkfill" Composite has been introduced on the market, enabling up to $4 \mathrm{~mm}$ thick increments to be cured in one step, thus skipping the time-consuming layering technique ${ }^{[10,11]}$. As a result of continuing efforts to simplify daily clinical treatment procedures and to decrease handling errors, a new category of flowable composites, the so-called self-adhering flowable resin composite was introduced that combines the properties of self-adhesion and flowability ${ }^{[12]}$. Restorations with these composites eliminate the need of etching and bonding steps that normally required for bonding a conventional flowable composites to enamel and dentin ${ }^{[13]}$.

The surface texture is considered one of several important properties that has been used to evaluate and predict the success and longevity of restorations constructed from different types of materials ${ }^{[14]}$. The increased surface roughness of tooth colored restorative materials may contributes to plaque retention and residues accumulation resulting in gingival inflammation, surface discoloration, and secondary caries ${ }^{[15,16]}$. In addition, surface roughness may affects wear resistance and marginal integrity of posterior restorations ${ }^{[17,18]}$. Therefore, the achievement of highly surface smoothness is essential for the success, esthetical appearance and longevity of composite restorations, as well as to obtain a healthy surrounding periodental tissues ${ }^{[1,19]}$. Furthermore, a smooth surface enhances patient's comfort because surface roughness of $0.3 \mu \mathrm{m}$ can be perceived by the tongue tip ${ }^{[20]}$.

Application of topical fluoride agents to tooth surface have been suggested as effective mechanism in preventing dental caries and control the formation of enamel lesions during fixed orthodontic treatment ${ }^{[21]}$. In addition, fluoride application has the ability for remineralization of demineralized enamel when adequate amounts of calcium and phosphate ions are available ${ }^{[22]}$. The most commonly used fluoride agents are acidulated phosphate fluoride (APF), stannous fluoride ( $\mathrm{SnF} 2)$, and sodium fluoride $(\mathrm{NaF})$ gels ${ }^{[23,24]}$. However, APF agents have been suggested to produce superficial erosion of composite restorations and has a deterioration effects on surface roughness of glassionomer and composite materials ${ }^{[14,25,26]}$. On the other hand, stannous fluoride and sodium fluoride gels have been found to produce adverse effects on the surface roughness and topography of composite restorative materials ${ }^{[24]}$.

Recently, a milk protein derivative, casein phosphopeptide-amorphous calcium phosphate (CPP-ACP) complex, has been developed for caries prevention and enamel remineralization, taking the advantage of anticariogenic effect of milk ${ }^{[27,28]}$. CPP-ACP has been trademarked Recaldent and more recently, a sugar-free, water-based creams containing CPP-ACP; named GC Tooth Mousse and its fluoridated form GC Tooth Mousse Plus; have been made available to dental professionals. Casein phosphopeptides (CPP) have greater ability to stabilize nano clusters of amorphous calcium 
phosphate (ACP) by forming CPP-ACP complexes, preventing calcium phosphate growth to the critical size required for nucleation, transformation, and subsequent precipitation ${ }^{[29,30]}$. Thus, CPP has a significant ability to stabilize calcium and phosphate and keep them in a soluble, amorphous state (ionic form) that can infiltrate into enamel and repair areas that have been damaged by plaque bacteria. This is the basis of preventing and reversing teeth caries ${ }^{[27-30]}$. CPP also stabilizes fluoridated amorphous calcium phosphate (ACPF), which has a greater remineralization effect on caries lesions than fluoride and CPP-ACP alone [22,31,32]. CPP$\mathrm{ACP}$ has established to have anticariogenic activity and promote enamel subsurface remineralization in laboratory, animal, and human in situ experiments $^{[29,31,33-35]}$.

The mode of action of CPP-ACP has been suggested that CPP-ACP binds well to the tooth surface and to bacteria in the plaque. Thus, CPPACP localizes a high concentration of ACP in close proximity to the tooth surface and acts as a reservoir of calcium and phosphate ions. Therefore, this localized CPP-ACP, under acidic conditions, buffers the free calcium and phosphate ions and markedly increasing calcium phosphate level in plaque, thereby maintaining a state of supersaturation that inhibits enamel demineralization and promotes remineralization $^{[27,29,33,34]}$. Another suggested mode of action of CPP-ACP is that its capacity to inhibit the adhesion of Streptococcus mutans to the tooth surface ${ }^{[36]}$. Rose indicated that CPPACP would compete with calcium for plaque calcium binding sites. Therefore, this will decrease the quantity of calcium bridging between the pellicle and adhering bacterial cells and between bacterial cells themselves ${ }^{[37]}$. This, as a result, could limit mineral loss and deliver a source of high free calcium that control demineralization and enhances remineralization ${ }^{[37]}$. Another unique feature of CPP-ACP, that reduces caries activity in a dose-dependent mechanism $[30,33,35]$, is that CPP-ACP treated enamel has been found to be more resistant to subsequent acid challenge ${ }^{[38]}$.
CPP-ACP has too many indications in dentistry such as remineralization early carious lesions, the treatment of white spot lesions, reducing tooth sensitivity, after bleaching, after removal of orthodontic brackets, caries stabilization, and fluorosis ${ }^{[39]}$.

Remineralizing agents used for caries prevention has been established to cause changes in surface texture of the tooth-colored restorative materials ${ }^{[24-26]}$. There is insufficient data available on the effect of the recent $\mathrm{CPP}-\mathrm{ACPF}$ remineralizing agent on the surface roughness of composite restorations. Therefore, this study was carried out to investigate and compare the effect of GC Tooth Mousse Plus with fluoride (CPP-ACPF) and Clinpro White Varnish (NaF with $\mathrm{TCP}$ ), remineralizing pasts, on surface texture of four different recently introduced dental restorative composites.

\section{MATERIALS AND METHODS}

Four different resin composite materials were investigated in this study. The materials and their specifications are listed in Table 1 . The shade used for all composite materials was A3.

\section{Specimens preparation}

Disc specimens ( $5 \mathrm{~mm}$ diameter $\times 2 \mathrm{~mm}$ thick) were prepared by using split Teflon mold. The mold was positioned on a celluloid matrix strip (KerrHawe, Bioggio, Switzerland) laying on a microscopic glass slide and slightly overfilled with the composite material. After inserting the material into the mold, a transparent celluloid strip was placed over it and another microscopic glass slide was used to compact the composite into the mold using finger pressure. Each composite specimen was photocured for $40 \mathrm{~s}$ using LED curing unit (Mini LED, Satelec, Acteon Group, France) with $1200 \mathrm{~mW} / \mathrm{cm}^{2}$ output power, holding the tip of the curing unit in direct contact with the overlaid glass slide to achieve maximum curing depth. The output intensity of the curing unit was verified with the built-in radiometer in the curing unit. Each specimen was then polished sequentially on top surface, under dry condition, 
with coarse, medium, fine, and extra-fine $\mathrm{Al} 2 \mathrm{O} 3$ abrasive discs (Poli-Pro Discs , Premier Dental Products Co., Norristown, PA, USA) mounted on a slow-speed hand piece rotating at $15000 \mathrm{rpm}$. A new set of discs was used with every specimen. This polishing system was used because it offers a safe center to protect the composite surface, where the mandrel in completely covered with the disc. Each polishing step was carried out for $15 \mathrm{sec}$ with light hand pressure in a planner motion. A planner motion, which is a rotational movement with the axis of rotation perpendicular to the specimen surface, was used as it was stated that this motion produced the lowest surface roughness ${ }^{[1,2]}$. After each polishing step, the specimen rinsed with water/ air spry for $10 \mathrm{sec}$, air dried for $5 \mathrm{sec}$, before starting polishing with a new disc of lower grit. To facilitate holding and proper positioning the specimen during polishing, the specimen was mounted in stainless steel matrix with central height adjustment ${ }^{[40]}$ and stabilized with lateral screw. The Specimens were ultrasonically cleaned in distilled water for $5 \mathrm{~min}$ in ultrasonic bath (L\&R Manufacturing, Keamy, NJ, USA). To minimize variability, all specimens preparation, finishing and polishing procedures were conducted with the same operator.

Twenty specimens were prepared from each composite and divided into four groups $(n=5)$ : group 1: without treatment, dry-stored at $37^{\circ} \mathrm{C}$ for 15 days; group 2: without treatment, stored in distilled water at $37^{\circ} \mathrm{C}$ for 15 days; group 3: treated with GC Tooth Mousse Plus (CPP-ACP with fluoride) $15 \mathrm{~min} /$ once daily for 15 consecutive days and stored in distilled water at $37^{\circ} \mathrm{C}$; and group 4: treated with Clinpro White Varnish (5\% NaF with TCP) 15 min/once daily for 15 consecutive days and stored in distilled water at $37^{\circ} \mathrm{C}$. Group 1 represented a control group which provides baseline measurements with which the surface roughness of other groups would be compared. Group 2 represented a negative control group to exclude the effect of distilled water on the surface roughness as groups 3 and 4 were stored in distilled water.

\section{Surface treatment}

The materials used in this study for surface treatment, their manufacturers, and compositions are listed in Table 2. The specimens of groups 3 and 4 were placed in distilled water for $24 \mathrm{~h}$ before the initiation of surface treatment. The specimen surface was gently air dried to remove excess water before application of treatment past materials. GC Tooth Mousse Plus and Clinpro White Varnish were applied on the top surface of each specimen of their respective groups in an amount that completely cover the surface using fiber tip applicator (3M-ESPE, St. Paul, MN, USA). At the end of each treatment phase, each specimen was thoroughly washed with compressed air/water spray for $30 \mathrm{sec}$, then placed in fresh distilled water $\left(37^{\circ} \mathrm{C}\right)$ until the next treatment application at next day. This procedure was repeated daily for consecutive 15 days.

\section{Surface roughness and topography measurements}

The surface roughness and topography of all specimens were analyzed using non-contact Bruker ContourGT 3D Optical Profiler (Bruker, Tucson, AZ, USA; Fig. 1) that is installed on TMC vibration control table (Technical Manufacturing Corporation, USA). This device combines advanced Vision64 (multi-core operation and analysis software) that enables fast and comprehensive data collection and analysis, patented white light interferometric (WLI) hardware, and unprecedented operator ease-of-use; to deliver the most advanced 3D optical surface profilers. The ContourGT is a 3D optical microscope, based on WLI, that provides precise 3D topography of an object's surface. Its measurement accuracy is in the single-digit nanometer range and can measure changes in surface height within a single field of view up to 10 millimeters in difference. It has the advantage of providing fast, sub-nanometer resolution metrology over large fields of view, and flexible sample setup ${ }^{[41]}$. The way that this 3D microscope works can be simply described as follows: there is a light source and sets of optics that serve to bring that light to beam splitter, which takes 
the beam down through a microscope objective to the sample surface, then the light reflected from the sample and from the reference surface within the special objective back to the camera detector array up at the top of the image and by scanning through focus at the position of sample measurement, it can build up an extremely accurate 3D picture of the surface $^{[41]}$.

The following amplitude roughness parameters were measured: Sa, roughness average profile, (the arithmetic average of the absolute distance of the roughness profile from the mean line taken within the measuring area); $\mathrm{Sq}$ (the root mean square deviation of the measured roughness profile); $\mathrm{Sz}$ (the average value of the five highest peaks and the five deepest valleys over the evaluation length); $\mathrm{Sp}$ (the maximum peak height from the mean plan), $\mathrm{Sv}$ (the maximum valley depth from the mean plan).
Three measurements were taken from each specimen and the mean value of these measurements on one specimen was regarded as the roughness parameter of that specimen.

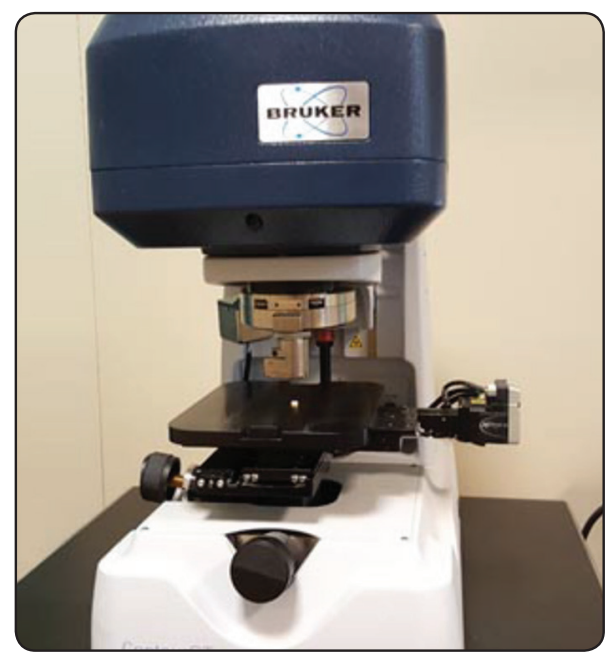

Fig. (1) Bruker ContourGT 3D Optical Profiler

TABLE (1) Specifications of resin composite materials evaluated in this study.

\begin{tabular}{|c|c|c|l|c|}
\hline Product & \multicolumn{1}{|c|}{ Type } & Manufacture & \multicolumn{1}{|c|}{ Chemical Composition } & Filler (wt\%) \\
\hline $\begin{array}{c}\text { Filtek Z250 XT } \\
\text { (F250) }\end{array}$ & $\begin{array}{c}\text { Nano-hybrid } \\
\text { universal } \\
\text { composite }\end{array}$ & $\begin{array}{c}\text { 3M-ESPE, } \\
\text { St paul, MN, } \\
\text { USA. }\end{array}$ & $\begin{array}{l}\text { Resin matrix: Bis-GMA, UDMA, Bis-EMA,TEGDMA. } \\
\text { Filler: Silica (20 nm), zirconia/silica clusters (0.1-10 } \\
\mu \mathrm{m}) .\end{array}$ & $81.8 \%$ \\
\hline $\begin{array}{c}\text { Filtek Z350 XT } \\
\text { (F350) }\end{array}$ & $\begin{array}{c}\text { Nano-filled } \\
\text { flowable } \\
\text { composite }\end{array}$ & $\begin{array}{c}\text { 3M-ESPE, } \\
\text { St paul, MN, } \\
\text { USA. }\end{array}$ & $\begin{array}{l}\text { Resin matrix: Bis-GMA, UDMA, TEGDMA, Bis- } \\
\text { EMA, PEGDMA. } \\
\text { Filler: Silica (20 nm), zirconia (4-11 nm), zirconia/ } \\
\text { silica clusters (0.6-10 } \mu \text { m). }\end{array}$ & $78.5 \%$ \\
\hline $\begin{array}{c}\text { Filtek Bulk Fill } \\
\text { Restorative } \\
\text { Posterior } \\
\text { (FBF) }\end{array}$ & $\begin{array}{c}\text { Nano-hybrid } \\
\text { high viscosity } \\
\text { bulk fill } \\
\text { composite }\end{array}$ & $\begin{array}{c}\text { 3M-ESPE, } \\
\text { St paul, MN, } \\
\text { USA. }\end{array}$ & $\begin{array}{l}\text { Resin matrix: AUDMA, AFM, UDMA, DDDMA. } \\
\text { Filler: Silica (20 nm), zirconia (4-11 nm), zirconia/ } \\
\text { silica clusters, ytterbium fluoride (100 nm } \\
\text { agglomerate particles). }\end{array}$ & $76.5 \%$ \\
\hline $\begin{array}{c}\text { Vertise Flow (FV) } \\
\text { Mico-hybrid } \\
\text { self-adhering } \\
\text { flowable } \\
\text { composite }\end{array}$ & $\begin{array}{c}\text { Kerr, Orange, } \\
\text { CA, USA. }\end{array}$ & $\begin{array}{l}\text { Resin matrix: GPDM, HEMA, Methacrylate co- } \\
\text { polymer. } \\
\text { Filler: PPF, barium glass (1 } \mu \text { ), silica (10-40 nm), } \\
\text { ytterbium fluoride (40 nm). }\end{array}$ & $70 \%$ \\
\hline
\end{tabular}

Bis-GMA: Bisphenol A glycidly dimethacrylate; UDMA: Urethan dimethacrylate; Bis-EMA: Bisphenol-A polyethylene glycol diether dimethacrylate; TEGDMA: Triethyene glycol dimethacrylate; PEGDMA: Polyethyene glycol dimethacrylate; AUDMA: Aromatic dimethacrylate; AFM: Addition fragmentation monomer; DDDMA: Dodeconated dimethacrylate; GPDM: Glycerol phosphate dimethacrylate; HEMA: Hydroxyethyl methacrylate; PPF : Prepolymerized filler. 
TABLE (2) Specifications of treatment materials used in this study.

\begin{tabular}{|l|l|l|l|}
\hline \multicolumn{1}{|c|}{ Product } & Effective component & \multicolumn{1}{|c|}{ Manufacture } & \multicolumn{1}{c|}{ Composition } \\
\hline $\begin{array}{l}\text { GC Tooth } \\
\begin{array}{l}\text { Mousse Plus } \\
\text { (TMP) }\end{array}\end{array}$ & CPP-ACP & $\begin{array}{l}\text { GC Corporation, } \\
\text { Tokyo, Japan. }\end{array}$ & $\begin{array}{l}\text { Pure water, glycerol, CPP-ACP, D-sorbitol, CMC-Na, propylene } \\
\text { glycol, silicone dioxide, titanium dioxide, xylitol, phosphoric acid, } \\
\text { flavoring, zinc oxide, sodium saccharin, ethyl p-hydroxybenzoate, } \\
\text { propyl p-hydroxybenzoate, butyl p-hydroxybenzoate, 0.2\% } \\
\text { sodium fluoride (900 ppm). }\end{array}$ \\
\hline $\begin{array}{l}\text { Clinpro White } \\
\text { Varnish (CWV) }\end{array}$ & NaF 5\% & $\begin{array}{l}\text { 3M-ESPE, } \\
\text { St paul, MN, USA. }\end{array}$ & $\begin{array}{l}\text { Resin, alcohol, sodium fluoride, tri-calcium phosphate (TCP), } \\
\text { water, xylitol, flavor. }\end{array}$ \\
\hline
\end{tabular}

\section{Statistical analysis}

Two-way ANOVA multiple comparison tests were used for statistical analysis to assess the significant effect of surface treatment, material type, and their interaction on all surface roughness parameters. A series of one way ANOVA followed by Tukey HSD multiple comparison tests were done to analyze differences in surface roughness parameters among surface treatment groups and among different materials within each group independently. Statistical significance was defined at $\mathrm{P}<0.05$. All statistical analysis were carried out using SPSS software program version 16.0 (SPSS Inc., Chicago, IL).

\section{RESULTS}

The means and standard deviations of surface roughness parameters for the different groups of all materials investigated are presented in tables 4 to 8 . $3 \mathrm{D}$ surface images of representative specimens of each material and surface treatment are displayed in figure 2. Two-way ANOVA results (Table 3) indicated that there were high significant differences among treatment groups of each material $(\mathrm{P}<0.001)$, among materials within each group $(\mathrm{P}<0.001)$ and the interaction between them $(\mathrm{P}<0.001)$; for all roughness parameters.

One-way ANOVA showed that the effect of remineralizing agents on all surface roughness parameters per resin composite material was significant $(\mathrm{P}<0.001)$. The results of Tukey multiple comparisons demonstrated that for all investigated composites, the treatment with TMP had no significant $(\mathrm{P}>0.05)$ effect on surface roughness parameters values, while the treatment with $C W V$ produced significantly $(\mathrm{P}<0.001)$ higher values of the same parameters; in comparison to the air-stored (control) group. Also the values of all roughness parameters of water-stored group for each tested composite were significantly $(\mathrm{P}<0.001)$ higher compared to air-stored group. If the control group excluded, the TMP-treated group exhibited significantly $(\mathrm{P}<0.001)$ lower values of roughness parameters in comparison to both water-stored and CWV-treated groups for all materials tested except between TMP-treated and water-stored groups of $\mathrm{VF}$, where no significant $(\mathrm{P}>0.05)$ difference was noted between them. Compared to water-stored group, the CWV-treated group of each investigated composite produced significantly $(\mathrm{P}<0.001)$ higher values of $\mathrm{Sa}, \mathrm{Sq}$, and $\mathrm{Sz}$ parameters; but not for $\mathrm{Sp}$ and $\mathrm{Sv}$ parameters. Roughness average $(\mathrm{Sa})$ of all materials with their treatment groups are presented graphically in Fig. 3.

One-way ANOVA revealed that the effect of material was also significant $(\mathrm{P}<0.001)$ within each treatment group and control group regarding all parameter. The results of $\mathrm{Sa}$ and $\mathrm{Sq}$ parameters of the dry-stored (control) group and TMP-treated group were similar, where all composite materials were significantly $(\mathrm{P}<0.001)$ different from each 
other regarding these parameters, with F350 had the lowest mean values and VF had the highest mean values. In both groups, also F350 exhibited significantly $(\mathrm{P}=0.003)$ lower roughness value than that of F250 (Tables 4 and 5). Regarding waterstored group, F350 and F250 produced statistically $(\mathrm{P}=0.83)$ comparable $\mathrm{Sa}$ and $\mathrm{Sq}$ values, which are significantly $(\mathrm{P}<0.01)$ lower than those of FBF and VF. At the same time, the $\mathrm{Sa}$ and $\mathrm{Sq}$ values of FBF was significantly $(\mathrm{P}<0.05)$ lower than those of VF. In respect to CWV-treated group,
VF displayed the significant $(\mathrm{P}<0.001)$ highest $\mathrm{Sa}$ and $\mathrm{Sq}$ values, while $\mathrm{F} 350$ revealed the significant $(\mathrm{P}<0.001)$ lowest values of the same parameters. However, no significant $(\mathrm{P}>0.05)$ differences were noted between F250 and FBF (Tables 4 and 5). For all other parameters, there were also significant differences $(\mathrm{P}<0.001)$ among different materials within each treatment or storage condition, but the ordering of materials fluctuated with the different conditions and respecting the different parameters as shown in Tables 6-8.

TABLE (3) Two-way ANOVA results (P values) in this study

\begin{tabular}{|c|c|c|c|c|c|}
\hline & $\mathrm{Sa}$ & $\mathrm{Sq}$ & $\mathrm{Sz}$ & $\mathrm{Sp}$ & $\mathrm{Sv}$ \\
\hline Material & 0.000 & 0.000 & 0.000 & 0.000 & 0.000 \\
\hline Surface treatment & 0.000 & 0.000 & 0.000 & 0.000 & 0.000 \\
\hline Material/ treatment & 0.000 & 0.000 & 0.000 & 0.000 & 0.000 \\
\hline
\end{tabular}

TABLE (4) Sa (means and SD; $\mu \mathrm{m}$ ) of all composite materials tested.

\begin{tabular}{|c|c|c|c|c|}
\hline & Dry & Water & TMP & CWV \\
\hline F250 & $0.10(0.01)^{\mathrm{a} / 1}$ & $0.13(0.01)^{\mathrm{b} / 1}$ & $0.10(0.00)^{\mathrm{a} / 1}$ & $0.17(0.01)^{\mathrm{c} / 1}$ \\
\hline F350 & $0.09(0.01)^{\mathrm{a} / 2}$ & $0.13(0.01)^{\mathrm{b} / 1}$ & $0.09(0.00)^{\mathrm{a} / 2}$ & $0.15(0.01)^{\mathrm{c} / 2}$ \\
\hline FBF & $0.11(0.01)^{\mathrm{a} / 3}$ & $0.14(0.01)^{\mathrm{b} / 2}$ & $0.11(0.01)^{\mathrm{a} / 3}$ & $0.17(0.01)^{\mathrm{c} / 1}$ \\
\hline VF & $0.12(0.00)^{\mathrm{a} / 4}$ & $0.15(0.01)^{\mathrm{b} / 3}$ & $0.15(0.00)^{\mathrm{b} / 4}$ & $0.23(0.01)^{\mathrm{c} / 3}$ \\
\hline
\end{tabular}

Different superscript lower case letters in the same raw indicating statistically significant differences $(p<0.01)$.

Different superscript numbers in the same column indicating statistically significant differences $(p<0.05)$.

TABLE (5) Sq (means and SD; $\mu \mathrm{m}$ ) of all composite materials tested.

\begin{tabular}{|c|c|c|c|c|}
\hline & Dry & Water & TMP & CWV \\
\hline F250 & $0.15(0.02)^{\mathrm{a} / 1}$ & $0.17(0.02)^{\mathrm{b} / 1}$ & $0.15(0.02)^{\mathrm{a} / 1}$ & $0.25(0.05)^{\mathrm{c} / 1}$ \\
\hline F350 & $0.13(0.01)^{\mathrm{a} / 2}$ & $0.17(0.02)^{\mathrm{b} / 1}$ & $0.13(0.01)^{\mathrm{a} / 2}$ & $0.23(0.04)^{\mathrm{c} / 2}$ \\
\hline FBF & $0.15(0.02)^{\mathrm{a} / 1}$ & $0.19(0.01)^{\mathrm{b} / 2}$ & $0.17(0.02)^{\mathrm{a} / 3}$ & $0.25(0.06)^{\mathrm{c} / 1}$ \\
\hline VF & $0.16(0.01)^{\mathrm{a} / 1}$ & $0.21(0.02)^{\mathrm{b} / 3}$ & $0.20(0.01)^{\mathrm{b} / 4}$ & $0.32(0.03)^{\mathrm{c} / 3}$ \\
\hline
\end{tabular}

Different superscript lower case letters in the same raw indicating statistically significant differences $(p<0.01)$. Different superscript numbers in the same column indicating statistically significant differences $(p<0.05)$. 
TABLE (6) $\mathrm{Sz}$ (means and $\mathrm{SD} ; \mu \mathrm{m}$ ) of all composite materials tested.

\begin{tabular}{|c|c|c|c|c|}
\hline & Dry & Water & TMP & CWV \\
\hline F250 & $4.03(1.59)^{a / 1}$ & $6.33(1.98)^{\mathrm{b} / 1}$ & $3.94(1.22)^{\mathrm{a} / 1}$ & $9.21(2.02)^{\mathrm{c} / 1,3}$ \\
\hline F350 & $3.67(1.83)^{\mathrm{a} / 1}$ & $7.17(2.13)^{\mathrm{b} / 1,2}$ & $4.97(2.14)^{\mathrm{a} / 1}$ & $9.01(1.67)^{\mathrm{c} / 1,2}$ \\
\hline FBF & $6.08(1.43)^{\mathrm{a} / 2}$ & $8.96(2.94)^{\mathrm{b}, \mathrm{c} / 2}$ & $6.83(1.38)^{\mathrm{a} / 2}$ & $10.51(1.51)^{\mathrm{c} / 3}$ \\
\hline VF & $5.58(1.37)^{\mathrm{a} / 2}$ & $12.38(3.74)^{\mathrm{b} / 3}$ & $11.00(2.03)^{\mathrm{b} / 3}$ & $14.35(3.52)^{\mathrm{c} / 4}$ \\
\hline
\end{tabular}

Different superscript numbers in the same column indicating statistically significant differences $(p<0.01)$.

Different superscript lower case letters in the same raw indicating statistically significant differences $(p<0.05)$.

TABLE (7) Sp (means and SD; $\mu \mathrm{m}$ ) of all composite materials tested.

\begin{tabular}{|c|c|c|c|c|}
\hline & Dry & Water & TMP & CWV \\
\hline F250 & $2.46(0.69)^{\mathrm{a} / 1}$ & $3.88(1.06)^{\mathrm{b} / 1}$ & $2.43(0.89)^{\mathrm{a} / 1}$ & $4.42(0.68)^{\mathrm{b} / 1,2,3}$ \\
\hline F350 & $1.59(0.60)^{\mathrm{a} / 2}$ & $4.23(1.28)^{\mathrm{b} / 1,3}$ & $2.17(1.48)^{\mathrm{a} / 1}$ & $3.68(1.08)^{\mathrm{b} / 2}$ \\
\hline FBF & $2.41(0.79)^{\mathrm{a} / 1}$ & $4.79(2.43)^{\mathrm{b} / 3}$ & $2.84(1.31)^{\mathrm{a} / 1}$ & $5.13(1.79)^{\mathrm{b} / 3}$ \\
\hline VF & $2.09(0.89)^{\mathrm{a} / 1,2}$ & $6.58(2.11)^{\mathrm{b} / 4}$ & $4.77(0.90)^{\mathrm{b} / 2}$ & $4.61(1.88)^{\mathrm{b} / 1,2,3}$ \\
\hline
\end{tabular}

Different superscript lower case letters in the same raw indicating statistically significant differences $(p<0.01)$.

Different superscript numbers in the same column indicating statistically significant differences $(p<0.05)$.

TABLE (8) Sv (means and SD; $\mu \mathrm{m}$ ) of all composite materials tested.

\begin{tabular}{|c|c|c|c|c|}
\hline & Dry & Water & TMP & CWV \\
\hline F250 & $-3.29(0.79)^{\mathrm{a} / 1}$ & $-4.47(1.53)^{\mathrm{b} / 1}$ & $-2.85(0.70)^{\mathrm{a} / 1}$ & $-4.44(1.51)^{\mathrm{b} / 1}$ \\
\hline F350 & $-2.11(0.86)^{\mathrm{a} / 2}$ & $-4.22(1.46)^{\mathrm{b} / 1,2}$ & $-2.62(1.02)^{\mathrm{a} / 1,2}$ & $-4.17(1.35)^{\mathrm{b} / 1}$ \\
\hline FBF & $-3.07(0.98)^{\mathrm{a} / 1}$ & $-5.78(1.56)^{\mathrm{b} / 2,3}$ & $-3.26(1.01)^{\mathrm{a} / 2}$ & $-5.46(2.12)^{\mathrm{b} / 1,2}$ \\
\hline VF & $-2.66(1.05)^{\mathrm{a} / 1,2}$ & $-7.00(3.01)^{\mathrm{b} / 3}$ & $-6.65(2.37)^{\mathrm{b} / 3}$ & $-6.91(1.94)^{\mathrm{b} / 2}$ \\
\hline
\end{tabular}

Different superscript lower case letters in the same raw indicating statistically significant differences $(p<0.01)$.

Different superscript numbers in the same column indicating statistically significant differences $(p<0.05)$.

\section{DISCUSSION}

Modern dentistry aims to manage non cavitated carious lesions with minimal intervention through remineralization in an attempt to prevent caries progression and to improve esthetics of teeth. Daily topical fluoride application for patients with a high caries index were shown to reduce the incidence of caries and arrest existing lesions ${ }^{[42]}$. However, topically applied fluorides were found to produce significant negative effects on the surface texture and composition of composite restorations [24], and thus it is advocated when using a fluoridated agents for caries-prevention that the clinician should be careful not to allow the agent to come 
into contact with the composite restorations ${ }^{[25]}$. In recent years, the use of calcium phosphatebased technologies have also been advocated to prevent demineralization and promote lesion remineralization ${ }^{[27-35]}$. Due to the above mentioned adverse effects of topically applied fluorides on composite materials and with the introduction of the new remineralizing agent, GC Tooth Mousse Plus, based on Recaldent (CPP-ACP) technology, this study was conducted to assess and compare the effect of this new remineralizing agent and a fluoride-based agent (Clinpro White Varnish) on surface texture of four different recently introduced dental restorative composites.
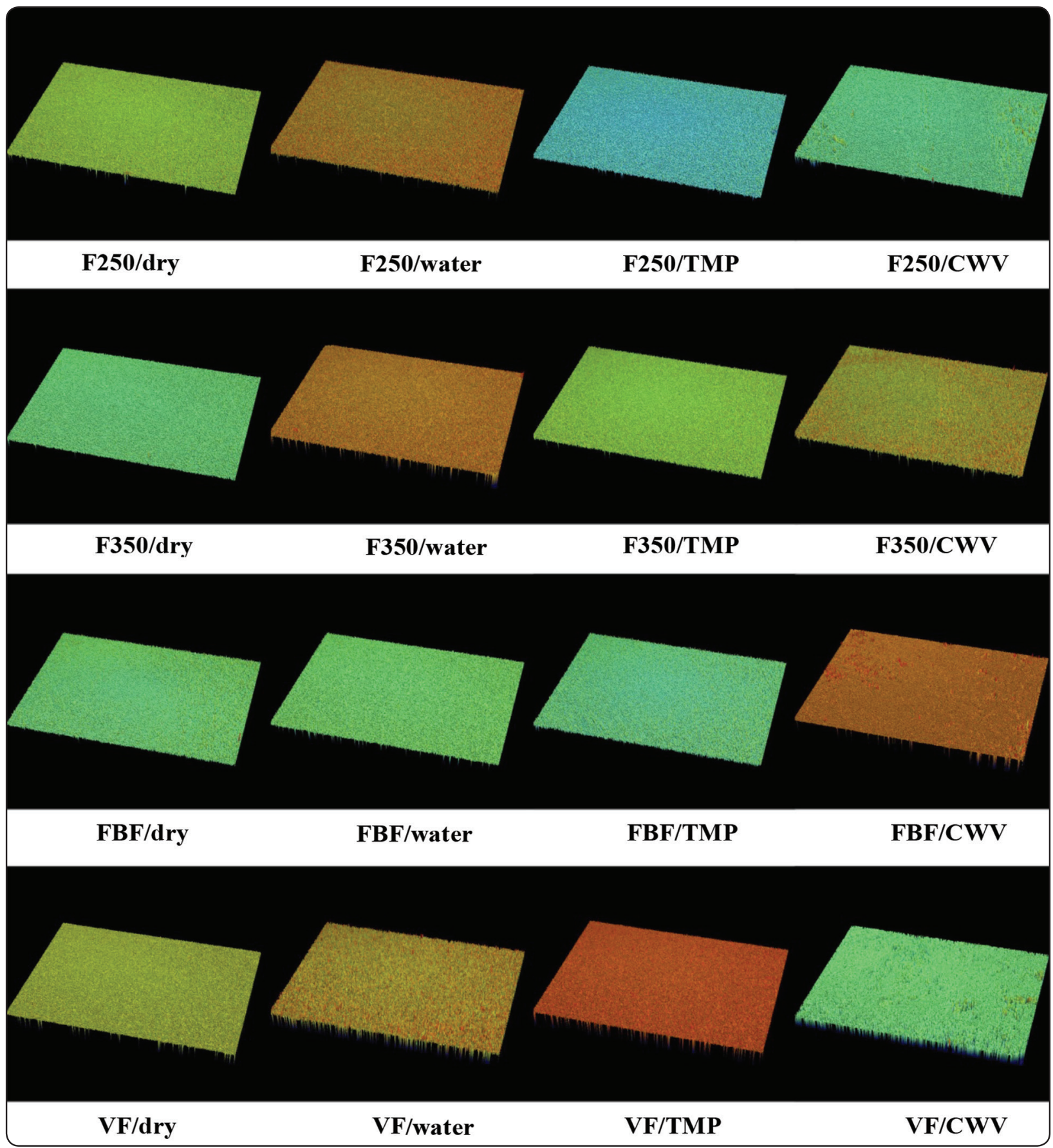

Fig. (2) 3D surface images of representative samples of the composite materials with their surface treatment groups. 


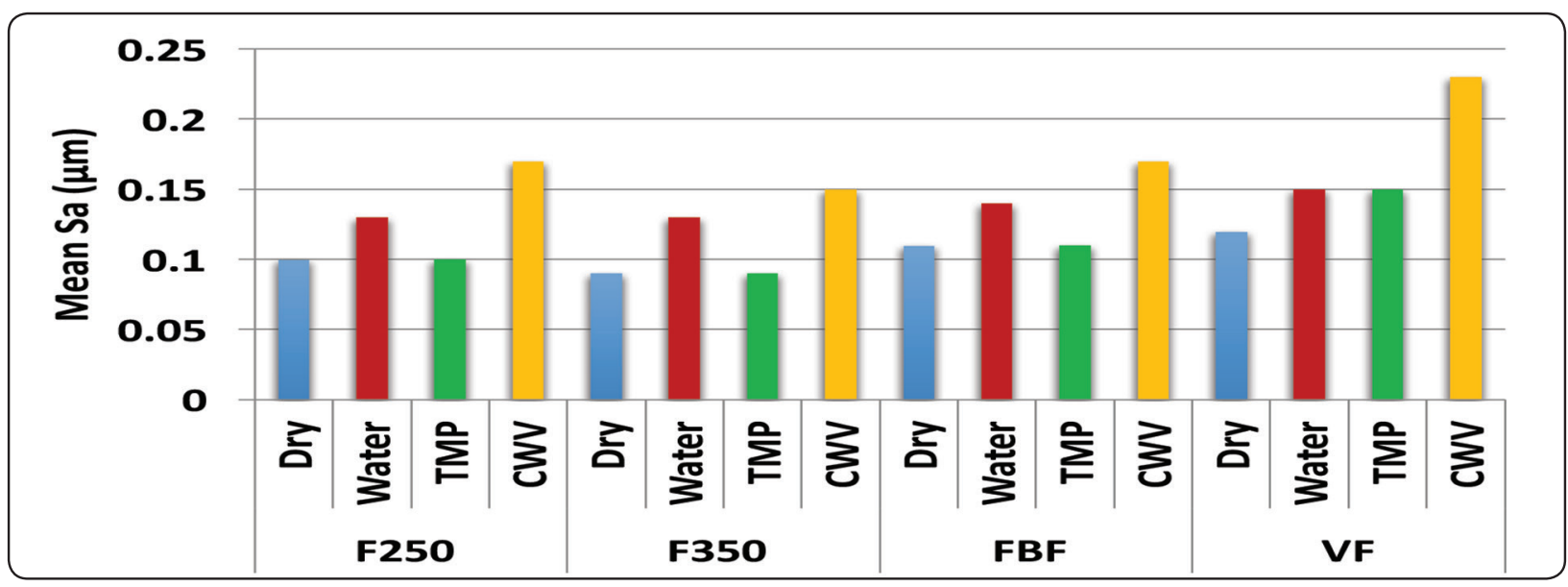

Fig. (3) Roughness average (Sa) of all materials with their treatment groups

TMP remineralizing agent that is used in this study was based on CPP-ACP like the regular GC Tooth Mousse, but it is enhanced with 900 ppm fluoride [38]. For each 2 fluoride ions, 10 calcium ions and 6 phosphate ions are required to form one unit cell of fluoroapatite $\left[\mathrm{Ca}_{10}\left(\mathrm{Po}_{4}\right)_{6} \mathrm{~F}_{2}\right]^{[43]}$. This is the same bio-available ratio that is used in the production of TMP ${ }^{[38]}$, and according to the available information, it is the only product that contains this ratio. However, the other remineralizung agent used in this study is the CWV, $5 \%$ sodium fluoride with tri-calcium phosphate (TCP). The TCP ingredient uses an innovative technology customized to work with CWV ${ }^{[44]}$. During the manufacturing process, a protective barrier is created around the calcium, while the phosphate is free, which prevents the calcium from prematurely reacting with fluoride before reaching the tooth surface. This barrier is broken once the varnish flows on the teeth and comes into contact with saliva, making calcium, phosphate and fluoride ions available to the teeth ${ }^{[45]}$.

In the present study, the storage medium was carried out by soaking the specimens in distilled water at $37{ }^{\circ} \mathrm{C}$, similar to many previous studies [46-48]. Artificial saliva has been considered a more clinically relevant storage medium [47-48]. Nonetheless, Turssi et al. ${ }^{[47]}$, reported similar results for the effect of distilled water and artificial saliva, as storage mediums, on the surface roughness of resin-based composites. Yap et al. ${ }^{[48]}$, also reported comparable degradation for composite materials after storage in distilled water and artificial saliva.

In most surface roughness experiments, the contact profilometry is the most commonly used method to measure the surface roughness of dental materials because it is generally available and relatively cheap ${ }^{[49,50]}$, but it is limited by the dimensions of stylus sensor, measuring force, and it usually underestimates the real roughness values $^{[51,52]}$. The stylus tip could not penetrate deep valleys because of its size and could not represent surface features, which are narrower than the stylus tip size. This problem results in underestimation of the surface roughness ${ }^{[53]}$. In the present study, the optical profiler was used for determining surface texture since it is documented that it provides a non-contact, 3D, higher resolution, non-destructive, and quick quantitative measurement for the surface texture ${ }^{[8,54]}$. 3D surface parameters are more representative than those achieved from $2 \mathrm{D}$ profiles. The data that can be obtained by 3D measurement gives a complete description of surface topography and is more complete than the $2 \mathrm{D}$ measurement ${ }^{[55]}$. 
The Ra parameter is the most commonly used parameter to indicate the surface roughness quantitatively ${ }^{[1,56]}$, but the use of other roughness parameters is supported, as $\mathrm{Ra}$ parameter alone does not illustrate the topography of the surface completely ${ }^{[57]}$. It has been reported that the other parameters are also related to biofilm adhesion, optical characteristics, and additional properties ${ }^{[58]}$.

The increase in surface roughness of all composite resin materials in the present study after water storage could be attributed to water sorption. Water can infiltrate into the resin matrix causing softening of the polymer component and through swelling can reduce the frictional forces between polymeric chains, resulting in hydrolytic degradation of the resin matrix with exposure of the filler particles ${ }^{[59,60]}$. Also, tensile stresses are created at the resin-filler interface, causing damage to the bonds in the inorganic component and reduction of the frictional forces between filler and resin matrix, resulting in fillers pull out ${ }^{[61]}$. It has been reported that Bis-GMA, UDMA, TEGDMA, and PEGDMA monomers have hydroxyl groups in their chemical structure, which promotes water sorption ${ }^{[62]}$ and since the methacrylate-based resin composites used in this study (F250, F350, FBF) have at least one or two of these monomers included in their resin matrix structure, this could explain the increased surface roughness of these materials after water storage. Moreover, the relative high water sorption of VF composite could be related to its GPDMbased monomer. GPDM monomer has an acidic phosphate functional group and two methacrylate functional groups ${ }^{[63]}$ and it is documented that the acidic resin monomers absorb higher water than neutral resin monomers ${ }^{[64]}$. The expected higher water uptake by VF resin composite, after water storage, might also be responsible for the significant higher roughness average value of this material in comparison to the other composites.

After application of TMP, it is observed that the roughness average $(\mathrm{Sa})$ value as well as the values of all other parameters ( $\mathrm{Sq}, \mathrm{Sz}, \mathrm{Sp}$, and $\mathrm{Sv}$ ) of all materials investigated, except VF, were significantly decreased as compared to those of water-stored groups, a decrease to the level that they became statistically non-significant when compared with the untreated control group. The same finding of roughness average value (Sa) was also recorded in a previous study, regarding F350 composite material ${ }^{[65]}$. In that study, it was suggested that MI Past Plus (the alternative name of Tooth Mousse Plus that is used in USA) might chemically attacked the inorganic filler particles, counteracting the water sorption effect on the resin matrix, resulting in surface smoothening. This effect could be attributed to the presence of phosphoric acid in the composition of the MI Paste Plus. Phosphoric acid has the ability to etch the filler particles ${ }^{[14]}$, that exposed after degradation of the superficial resin matrix due to water sorption and when these fillers are very small, as in the nanocomposite, the size of the defects left are practically undetectable, resulting in surface smoothening ${ }^{[65]}$. Another possible cause for a such smoothening effect could be attributed to the retention of CPPACP nano-clusters in the porosities created by water sorption ${ }^{[66]}$. On the other hand, the high roughness values of VF after application of TMP may be related to the large filler particles size of this microhybride composite in comparison to that of nano-composites. This finding agrees with that reported in a previous experiment ${ }^{[23]}$. Either the amount or the concentration of phosphoric acid contained in TMP might not be enough to produce sufficient etch of these large particles size to the limit to leave a smooth surface. The other explanation for that behavior might be the porosities or the defects developed after water storage by leaching out of unreacted monomers, degradation of resin matrix or dislodgement of large filler particles may be large to be substituted by the nano CCP-ACP complexes.

On the other hand, the application of CWV resulted in a high significant increase in the mean values of $\mathrm{Sa}, \mathrm{Sq}$, and $\mathrm{Sz}$ roughness parameters of 
all tested composite materials compared to those of water-stored groups as well as to those of TMPtreated and control groups. However, for $\mathrm{Sa}$ and Sv parameters, no significant difference was noted between CWV-treated and water-treated groups and both have values that are significantly higher than those of TMP-treated and control groups. The results in the present study regarding $\mathrm{Sa}$ values are comparable with those obtained in other studies ${ }^{[14,23,24]}$. It has been suggested that fluoride treatment of resin composite may cause dissolution and loss of filler particles, which may lead to more exposure of resin matrix and consequently increased hydrolytic effect. Fluoride ions are associated in the process of depolymerization reactions of the matrix-filler interface ${ }^{[24]}$. Papagiannoulis et al. ${ }^{[67]}$ stated that fluoride can disrupt the filler-matrix interface through three possible mechanisms: (1) hydrogen bonds of silanol groups are affected by rearrangement of the water monolayer adsorbed on filler, (2) hydrolysis of the organosilicon ester group, and (3) disorganization of the siloxane network formed from the condensation of intramolecular silanol groups, which stabilizes the interface. However, our findings are contrary to that of Botta et al. [66], who found that the topical application of APF did not cause alteration in surface roughness of FZ350. Such contrary could be related to the difference in the type and concentration of fluoride agents used. In that study, $1.23 \%$ APF gel was used, while in this study, $5 \% \mathrm{NaF}$ was applied. Fluoride agents with a high fluoride concentration has been reported to cause more surface deterioration of dental composites ${ }^{[68]}$.

In the present study, significant differences were observed among different composite resins within all groups, with VF showed the highest values of all roughness parameters, while F350 revealed the lowest values of the same parameters. It has been demonstrated that the surface roughness of the resin composite material is related to multiple factors such as filler (size,shape, type, and quantity), type of resin matrix, degree of conversion, and stability of filler-matrix interface ${ }^{[69,70]}$. Composite resins with smaller filler particles usually exhibited a smoother surface ${ }^{[71,72]}$. F350, which is nano-filled composite had almost the lowest roughness values, while VF, which is a microhybrid composite had the highest roughness values. During polishing, the nanoparticles can be worn away together with the resin matrix rather than pulling, leaving surfaces with smaller defects and better surface texture ${ }^{[73]}$, contrasting the rough surfaces noted in microhybrid composite such as FV. Generally, F250 and FBF nanohybrid composites displayed improved surface smoothness compared to VF, although it was less than that of F350. These results can be attributed to the composition of these composites, where nano fillers dislodgement is less likely to occur, while the large filler particles of microhybrid composite can be pulled away, leaving large pits or craters on the surface ${ }^{[66]}$. F250, F350, and FBF had higher filler content compared to $\mathrm{FV}$, since nanotechnology allows to get high filler loading of nano-composites. This high filler loading may be another reason that account for the decreased roughness values of these nano-composites in comparison to VF. Higher filler content is thought to protect the resin matrix from excessive abrasion during abrasion, leaving smoother surfaces ${ }^{[57]}$. Also, the strong filler-matrix combination of those composites lead to detaching the individual primary particles (nano-fillers) rather than the larger particles (clusters) during polishing, as with hybrid composites, leaving shallower and narrower defects and better smoother surfaces ${ }^{[57,74,75]}$. It has been suggested that the type of filler also influences the surface characteristic of the composite material ${ }^{[26,76]}$. Surface roughness of composite resins containing barium boro aluminum silicat are more susceptible to the effect APF gel ${ }^{[77]}$. Therefore, as barium is included in the filler composition of VF, it may be another factor responsible for the highest roughness values of this material in comparison to other materials, within the CWV-treated group. 
The mean critical value of surface roughness for bacterial colonization of several dental materials has been measured as $0.2 \mu \mathrm{m}{ }^{[78]}$. Above this value, increased bacterial colonization, dental plaque, and acid formation are expected, which could deteriorate the restorative material surface ${ }^{[14]}$. In the present study, all mean roughness average (Sa) values were less than this critical value, except for VF after CWV application.

\section{CONCLUSIONS}

Within the limitations of this in vitro study, the following conclusions can be drawn:

1. The surface texture of resin composites is dependent on both surface treatment and type of restorative composite, and there is a high significant correlation between the two factors.

2. Application of TMP produced a significant surface smoothening of all composites investigated, except VF, to the limit it is comparable to the control (dry-stored).

3. Application of CWV caused a significant increase in roughness values of all materials tested.

4. For all composites tested, TMP generally delivered a significant better surface texture than CWV.

\section{ACKNOWLEDGMENT}

The authors would like to thank Eng. Mohamed Elsharawy, College of Applied Medical Science, King Saud University, KSA, for his assistance in surface roughness test.

\section{REFERENCES}

1. Korkmaz Y, Ozel E, Attar N, Aksoy G. The influence of one-step polishing systems on the surface roughness and microhardness of nanocomposites. Oper Dent 2008;33:44-50.

2. Bashetty K, Joshi s. The effect of one-step and multi-step polishing systems on surface texture of two different resin composites. J Conserv Dent 2010;13:34-38.
3. Yap AU, Yap SH, Teo CK, Ng JJ. Finishing/polishing of composite and compomer restoratives: effectiveness of one-step systems. Oper Dent 2004;29:275-279.

4. Erdemir U, Yildiz E, Eren MM, Ozsoy A, Topcu FT. Effects of polishing systems on the surface roughness of tooth-colored materials. J Dent Sci 2013;8:160-169.

5. Beun S, Glorieux T, Devaux J, Vreven J, Leloup G. Characterization of nanofilled compared to universal and microfilled composites Dent Mater 2007;23:51-59.

6. Mozner N, Salz U. New developments of polymeric dental composites. Progress in polymer Sci 2001;26:535-576.

7. Ergucu Z, Turkun LS. Surface roughness of novel resin composites polished with one-step systems. Oper Dent 2007;32:185-192.

8. Janus J, Fauxpointa G, Arntze Y, Pelletier H, Etienne O. Surface roughness and morphology of three nanocomposites after two different polishing treatments by multi technique approach. Dent Mater 2010;26:416-425.

9. Terry DA. Direct applications of a nanocomposite resin system: Part 1- The evolution of contemporary composite materials. Practical Procedures \& Esthet Dent 2004; 16:417-422.

10. Do T, church B, Verissimo C, Hackmyer SP, Tantbirojn D, Simon JF, Versluis A. Cuspal flexure, Depth-of-cure, and bond integrity of bulk-fill composites. Pediatr Dent 2014;36:468-473.

11. Ilie N, Kessler A, Durner J. Influence of various irradiation processes on the mechanical properties and polymerization kinetics of bulk-fill resin based composites. J Dent 2013;41:695-702.

12. Rengo C, Goracci C, Juloski J, Chieffi N, Giovannetti A, Vichi A, Ferrari M. influence of phosphoric acid etching on microleakage of a self-etch adhesive and a self-adhering composite. Aust Dent J 2012;57:220-226.

13. Vichi A, Margvelashvili M, Goracci C, Papacchini F, Ferrari M. Bonding and sealing ability of a new selfadhering flowable composite resin in class I restorations. Clin Oral Invest 2013;17:1497-1506.

14. Yip KH, Peng D, Smales RG: Effect of APF gel on the physical structure of compomers and glass ionomer cements. Oper Dent 2001;26:231-238.

15. Morgan M. Finishing and polishing of direct posterior resin restorations. Pract Proced Aesthet Dent 2004;16:211-217.

16. Yap AUJ, Low JS, Ong LFKL. Effect of food-simulating liquids on surface characteristic of composite and polyacid-modified composite restoratives. Oper Dent 2000; 25:170-176. 
17. Yap AUJ, Tan S, The TY. The effect of polishing systems on microleakage of tooth coloured restoratives: part 1 . Conventional and resin-modified glass-ionomer cements. J Oral Rehabil 2000;27:117-123.

18. Ryba TM, Dunn WJ, Murchison DF. Surface roughness of various packable composites. Oper Dent 2002;27:243247.

19. Nagem Filho H, D'Azevedo MTFS, Nagem HD, Marsola FP. Surface roughness of composite resins after finishing and polishing. Brazilian Dent J 2003;14:37-41.

20. Jones CS, Billington RW, Pearson GL. The in vivo perception of roughness of restorations. $\mathrm{Br}$ Dent $\mathrm{J}$ 2004;196:42-45.

21. Donly KJ, Sasa IS. Potential remineralization of post orthodontic demineralized enamel and the use of enamel microabrasion and bleaching for esthetics. Semin Orthod 2008;14:220-225

22. Reynolds EC, Cai F, Cochrane NJ, Shen P, Walker GD, Morgan MV, et al. Fluoride and casein phosphopeptideamorphous calcium phosphate. J Dent Res 2008;87:344348.

23. Prabhakar AR, Mahantesh TB, Vishwas TD, Kabaded A. Effect of surface treatment with remineralizing on color the stability and roughness of esthetic restorative materials. Rev Clín Pesq Odontol 2009;5:19-27.

24. Jehad RH. Comparison of the effect of stannous fluoride and sodium fluoride on the surface roughness of silorane and methacrylate based restorative materials using light polarized microscope. J Baghdad College Dent 2011;23:31-35.

25. Turssi CP, de Magalhães CS, Serra MC. Effect of fluoride gels on micromorphology of resin-modified glassionomer cements and polyacid-modified resin composites. Quintessence Int 2001;32:571-577.

26. Soeno K, Matsumura H, Kawasaki K, Atsuta M. Influence of acidulated phosphate fluoride agents on surface characteristics of composite restorative materials. Am J Dent 2000;13:297-300.

27. Reynolds EC, Black CL, Cia F, Cross KJ, Eakins D, Huq NL, et al. . Advances in enamel remineralization: Casinphosphopeptide-Amorphous Calcium Phosphate. J Clin Dent 1999;10:86-88.

28. Oshiro $M$, Yamaguchi $K$, Takamizawa $T$, Inage $H$, Watanabe T, Irokawa A: Effect of CPP-ACP paste on tooth mineralization: an FE-SEM study. J Oral Science 2007;49:115-120
29. Reynolds EC. Remineralization of enamel subsurface lesions by casein phosphopeptide-stabilized calcium phosphate solutions. J Dent Res. 1997;76:1587-1595.

30. Shen P, Cai F, Nowicki A, Vincent J, Reynolds EC. Remineralization of enamel subsurface lesions by sugarfree chewing gum containing casein phosphopeptideamorphous calcium phosphate. J Dent Res. 2001;80:20662070.

31. Reynolds EC, Cai F, Shen P, Walker GD. Retention in plaque and remineralization of enamel lesions by various forms of calcium in a mouth rinse or sugar-free chewing gum. J Dent Res. 2003;82:206-211.

32. Srinivasan N, Kavitha M, Loganathan SC. Comparison of the remineralization potential of CPP-ACP and CPP-ACP with 900 ppm fluoride on eroded human enamel: An in situ study. Arch Oral Biol. 2010;55:541-544.

33. Reynolds EC, Cain CJ, Webber FL, et al. Anticariogenicity of calcium phosphate complexes of tryptic casein phosphopeptides in the rate. J Dent Res 1995;74:12721279.

34. Reynolds EC. Anticariogenic complexes of amorphous calcium phosphate stabilized by casein phosphopeptides: a review. Spec Care Dentist 1998;18:8-16.

35. Cia f, Shen P, Morgan MV, Reynolds EC. Remineralization of enamel subsurface lesions in situ by sugar-free lozenges containing casinophosphopeptide-amorphous calcium phosphate. Aust Dent J 2003;48:240-243.

36. Schupbach P, Neeser R, Golliard M, Rouvet M, Guggenheim B. incorporation of casinoglycomacropeptide and casinophosphopeptide into the salivary pellicle inhibits adherence of mutans streptococci. J Dent Res 1996;75:1779-1788.

37. Rose RK. Effects of an anticariogenic casein phosphopeptide on calcium diffusion in streptococcal model dental plaques. Arch Oral Biol. 2000;45:569-575.

38. Iijima Y, Cai F, Shen P, Walker G, Reynolds C, Reynolds EC. Acid resistance of enamel subsurface lesions remineralized by a sugar free chewing gum containing casein phosphopeptide-amorphous calcium phosphate. Caries Res 2004;38:551-556.

39. MI Paste MI Paste Plus Brochure: Anthology of Applications. Professor Laurie Walsh / University of Queensland, Australia. GC America Inc. www. gcamerica.com Accessed on January 15, 2017.

40. Botta AC, Duarte Jr S, Paulin Filho PI and Gheno SM. Effect of dental finishing instruments on the surface 
roughness of composite resins as elucidated by atomic force microscopy. Microscopy and microanalysis. 2008; 14:380-386.

41. ContourGT 3D optical microscopes. ContourGT/ ContourGT_3D_Optical_Microscopes-Brochure-B514RevC0.pdf Accessed on Jan 20, 2017.

42. Dreizen S, Daly $T$, Drane JB: Prevention of xerostomia-related dental caries in irradiated Cancer patients. J Dent Res 1997;56:99-104.

43. Cochrane NJ, Cai F, Huq NL, Burrow MF, Reynolds EC. New approaches to enhance demineralization of tooth enamel. J Dent Res. 2010;89:1187-97.

44. 3M ESPE, Clinpro White Varnish with TCP. www.3m. com/clinpro-white-varnish-brochure.pdf Accessed on Jan $12,2017$.

45. Karlinsey RL, Mackey AC, Walker ER, Frederick KE. Preparation, characterization, and in vitro efficacy of an acid-modified $\beta$-TCP material for dental hard-tissue remineralization. Acta Biometer 2010;6:969-978.

46. Ferracane JL, Berge HX, Condon JR. In vitro aging of dental composites in water--effect of degree of conversion, filler volume, and filler/matrix coupling. J Biomed Mater Res. 1998;42:465-472.

47. Turssi CP, Hara AT, Serra MC, Rodrigues AL Jr. Effect of storage media upon the surface micromorphology of resin-based restorative materials. J Oral Rehabil. 2002; 29:864-871.

48. Yap AU, Tan SH, Wee SS, Lee CW, Lim EL, Zeng KY. Chemical degradation of composite restoratives. J Oral Rehabil. 2001;28:1015-1021.

49. Turker SB, Biskin T. Effect of three bleaching agents on the surface properties of three different esthetic restorative materials. J Prosthet Dent 2003;89:466-473.

50. Wattanapayungkul P, Yap AU, Chooi KW, Lee MF, Selamat RS, et al. The effect of home bleaching agents on the surface roughness of tooth-colored restoratives with time. Oper Dent 2004;29:398-403.

51. Yazici AR, Muftu A, Kugel G. Three dimensional surface profile analysis of different types of flowable restorative resins following different finishing protocols. J Contemp Dent Pract 2007;8:9-19.

52. Kakaboura A, Fragouli M, Rahiotis C, Silikas N. Evaluationo of surface characteristics of dental composites using profilometry, scanning electron, atomic force microscopy and gloss-meter. J Mater Sci Mater Dent 2007; 18:155-163.
53. Wassell RW, McCabe JF, Walls AWG. Wear characteristics in a two-body wear test. Dent Mater 1994;10:269-274.

54. Joniot SB, Gregoire GL, Auther AN, Roques YM. Three dimensional optical profilometry analysis of surface states obtained after finishing sequences for three composite resins. Oper Dent 2000;25:810-819.

55. Marigo L, Rizzi M, Torre GL, Rumi G. 3-D surface profile analysis: different finishing methods for resin composites. Oper Dent 2001;26:562-568.

56. Ozel E, Korkomaz Y, Attar N, Karabulut E. Effect of onestep polishing systems on surface roughness of different flowable restorative materials. Dent Mater J 2008;27:755764.

57. Jung M, Sehr k, Klimek J. Surface texture of four nanofilled and one hybric composite after finishing. Oper Dent 2007;32:45-52.

58. Janus J, Fauxpointa G, Arntzc Y, Pelletier H, \& Etienne O. Surface roughness and morphology of three nanocomposites after two different polishing treatments by a multi technique approach. Dental Materials 2010; 26:416-425.

59. Catelan A, Briso ALF, Sundfeld RH, Dos Santos PH: Effect of artificial aging on the roughness and microhardness of sealed composites. J Esthet Rest Dent 2010;22(5):324-331.

60. Martos J, Osinaga PW, de Olivera E, de Casto LA. Hydrolytic degradation of composite resins: effects on the microhardness. J Mater res 2003;6:599-604.

61. Ferracane JL. Hygroscopic and hydrolytic effects in dental polymer networks. Dent Mater. 2006;22:211-222.

62. Yesilyurt C, Yoldas O, Altintas SH, Kusgos A: Effect of food-simulting liquids on the mechanical Properties of a silorane-based dental composite. Dent Mater J 2009:28:362-367.

63. Kerr. Vertise Flow: self-adhering flowable composite. Available at: http:/www.kerrdental.com/index/kerrdentalcomposites-vertiseflow-2. Accessed December 14, 2016.

64. Hosaka K, Nakajima M, Takahashi M, Itoh S, Ikeda M, Tagami J, Pashley DH. Relationship between mechanical properties of one-step self-etch adhesives and water sorption. Dent Mater 2010;26:360-367.

65. Hussien B. Effect of casein phosphopeptide-amorphous calcium phosphate on surface roughness of a siloranebased and methacrylate-based composite resin. (In vitro comparative study). J Bagh College Dent 2012; 24:106-111. 
66. Botta AC, Mollica FB, Ribreiro CF, de Araujo MAM, Di Nicolo R, Balducci I. Influence of topical acidulated phosphate fluoride on surface roughness of human enamel and different restorative materials. Rev. odonto cienc. 2010;25:83-87.

67. Papagiannoulis L, Tzoutzas J, Eliades G. Effect of topical fluoride agents on the morphological characteristics and composition of resin composite restorative materials. J Prosthet Dent 1997;77:405-413.

68. El-Badrawy WA, Mc Comb D, Wood RE. Effect of home-use fluoride gels on glass ionomer and composite restorations. Dent Mater 1993;9:63-67.

69. Ergucu Z, \& Turkun LS. Surface roughness of novel resin composites polished with one-step systems Oper Dent 2007;32:185-192.

70. Jefferies SR. The art and science of abrasive finishing and polishing in restorative dentistry. Dent Clin North Am 1998;42:613-627.

71. Bashetty K, \& Joshi S. The effect of one-step and multistep polishing systems on surface texture of two different resin composites. J Conserv Dent 2010;13:34-38.

72. Scheibe KGBA, Almeida KGB, Medeiros IS, Costa JF, \& Alves CMC. Effect of different polishing systems on the surface roughness of microhybrid composites. J Appl Oral Sci 2009;17:21-26.

73. Ereifej NS, Oweis YG, Eliades G. The effect of Polishing technique on 3-D surface roughness and gloss of dental restorative resin composites. Oper Dent 2013;38:9-20.

74. Jung M, Eichelberger K, \& Klimek J. Surface geometry of four nanofiller and one hybrid composite after one-step and multiple-step polishing. Oper Dent 2007;32:347-355.

75. Turssi CP, Ferracane JL, \& Serra MC. Abrasive wear of resin composites as related to finishing and polishing procedures. Dent Mater 2005;21:641-648.

76. Cehreli ZC, Yazici R, Garcia-Godoy F. Effect of 1.23 percent APF gel on fluoride releasing restorative materials. ASDC J Dent Child. 2000;67:330-337.

77. Yap AU and Mok BY. Effects of professionally applied topical fluorides on surface hardness of composite-based restoratives. Oper Dent 2002;27:576-581.

78. Bollen CML, Lambrechts P, Quirynen M. Comparison of surface roughness of oral hard materials to the threshold surface roughness for bacterial retention: a review of the literature. Dent Mater 1997;13:258-269. 